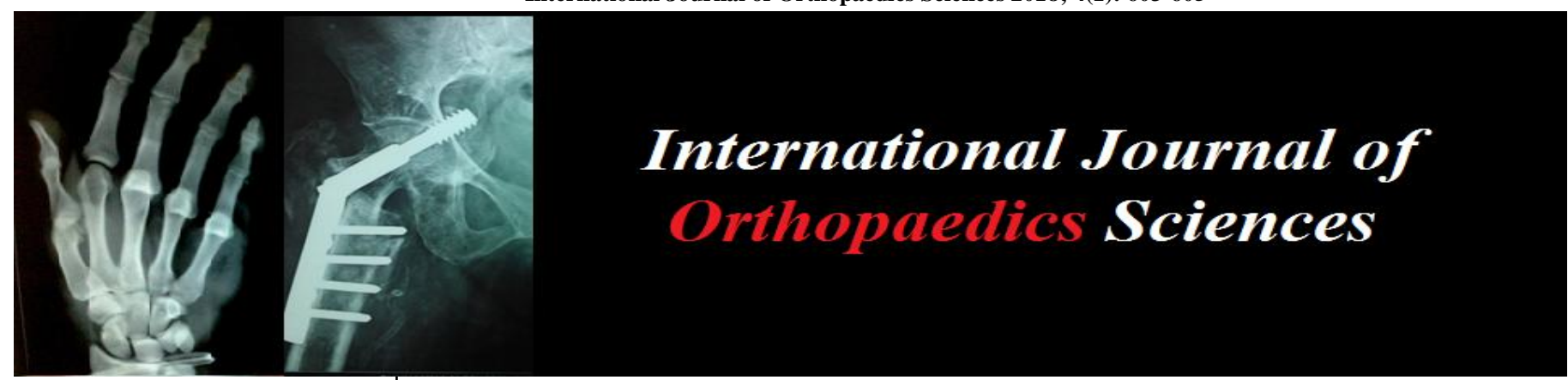

ISSN: $2395-1958$

IJOS 2018; 4(1): 603-605

(C) 2018 IJOS

www.orthopaper.com

Received: 07-11-2017

Accepted: 08-12-2017

Dr. Mallanagouda N Patil

Assistant Professor

Dept of Orthopaedics

Belagavi Institute of Medical

Sciences, Belgaum, Karnataka,

India
Dr. Mallanagouda N Patil

Assistant Professor

Dept of Orthopaedics

Belagavi Institute of Medical

Sciences, Belgaum, Karnataka,

India

\section{Treatment of ganglion by "needling": By transfixation suture, an effective and cosmetic way}

\section{Dr. Mallanagouda N Patil}

DOI: https://doi.org/10.22271/ortho.2018.v4.i1i.87

\section{Abstract}

Ganglion is commonly encountered problem across all age groups. It is one of the most common soft tissue tumors. Most commonly, patients seek treatment for cosmetic reason. Though there are variety of treatment options available, but very few are effective and cosmetically acceptable. Treatments like aspiration alone or in conjunction with hyaloronic acid or triamcinalone have higher recurrence rates. Hitting with book or bible is of historical significance. Surgical excision is best option available, but, leaves scar behind. In these circumstances, treatment by transfixation by no 1 mersilk suture under local anaesthesia on outpatient basis. This is effective as well as cosmetically acceptable method of treatment. In our series of 32 patients, which were treated by transfixation suture, had minimal complication. Silk used in this method helps in making track for escape of ganglion contents following initial procedure. And retaining suture lets the contents escape out and it produces fibrosis within ganglion lining. Thus reducing the chances of recurrences, compared to plain needling. As we call it "needling" is an excellent method with low recurrence, comparable to surgical excision with success rate of $90 \%$.

Keywords: Ganglion, Mersilk, needling

\section{Introduction}

The discussion about Ganglion, contains more questions than the answers. It is one of the most common soft tissue tumors, accounting for about $60-70 \%$ of soft tissue tumors ${ }^{[6]}$ Though this is very commonly encountered problem, there is no fixed treatment protocol. Ganglion is cystic lesion usually found on the dorsum of the wrist but also can be seen on the volar aspect of wrist and on the dorsal aspect of the ankle. On the dorsal side of the wrist, ganglion appears because of a rent in scapho-lunate capsular ligament. This has pinch cock effect leading to unidirectional flow of the contents, from the joint towards the cyst, until the pressure in the joint and cyst equalize ${ }^{[3]}$. There are varius treatment options utilized for the treatment of ganglion. They vary from hitting with book (bible) ${ }^{[7]}$, aspiration alone ${ }^{[5]}$, aspiration with hyaloronic acid injection ${ }^{[4]} /$ local steroid ${ }^{[6,9]}$ injection and lastly excision ${ }^{[2,3]}$. All these method have different rates of recurrence. Higher with aspiration alone and lower with surgical excision. Treatment of ganglion using thread method, we called it as needling,is very usefull. It is minimally invasive, has lower recurrence, less scaring ${ }^{[1]}$ as majority of the patients are females and cosmesis is one of the reason for intervention. Materials and methods Between January 2015 to December 2016, we studied 32 patients with ganglion. There were 26 female $(81.25 \%)$ patients and $6(18.75 \%)$ male patients. 28 of these were dorsal wrist ganglion $(87.5 \%), 2$ were volar ganglion (6.25) and remaining 2 were on dorsum of ankle (6.25\%). Majority of the patients seeking treatment were in third decade (table) and cosmesis was reason as compared to discomfort (table 4). All selected patients were fresh cases and none were recurrences. All patients were treated on outpatient basis. Parts were scrubbed and prepared like routine surgical procedure. Local anaesthetic agent (Lignocaine 2\% plain) was injected at the site of entry and exit of the needle. We used 1 no Mersilk/ simple surgical suture with taper cut needle for all the cases. Ganglion was punctured at one end with needle then the needle and thread were passed through the centre of the ganglion and exited from the opposite side of the ganglion, where local anaesthetic was given. Thread was moved to and fro, few times to create path. Then ganglion was pressed gently but firmly to express out the material. Clear paste like material 
was expressed out of the ganglion. Once most the contents are expressed out, mersilk was loosely tied over the top and dressing was done.

Patient was followed up on 3rd day for dressing. Bulky dressing was removed and while dressing ganglion is further pressed to express out any collection /filling up of ganglion contents and small wash proof dressing was applied, which allowed patient to take bath. And then on 7 th day of procedure patient was followed up and suture was removed. All the patients received oral antibiotics (cefuroxime $500 \mathrm{mg}$ bd for 3 days).Patient was encouraged to move wrist immediately after the procedure, which helps to express out the material through the intact tract of suture. Patents were then followed up at 1 month, 3 months and 1 year.

Table 1: Incidence

\begin{tabular}{|c|c|c|}
\hline Total & Female & Male \\
\hline 32 & $26(81.25 \%)$ & $6(18.75 \%)$ \\
\hline
\end{tabular}

Table 2: Site

\begin{tabular}{|c|c|c|c|}
\hline Site & Dorsal ganglion & Volar ganglion & Dorsum of ankle \\
\hline & $28(87.5)$ & $2(6.25 \%)$ & $2(6.25 \%)$ \\
\hline
\end{tabular}

Table 3: Age

\begin{tabular}{|c|c|}
\hline \multicolumn{2}{|c|}{ Age group } \\
\hline $10-20$ years & $8(25 \%)$ \\
\hline $20-30$ years & $18(56.25 \%)$ \\
\hline $30-40$ years & $6(18.75 \%)$ \\
\hline
\end{tabular}

Table 4: Reason for intervention

\begin{tabular}{|c|c|}
\hline Cosmesis & $18(56.25 \%)$ \\
\hline Pain while working & $16(43.75 \%)$ \\
\hline
\end{tabular}

\section{Results}

Of the 32 patients, 2 were lost to follow up after suture removal. 1 each of ganglion over foot and volar ganglion of wrist. Average duration of procedure proper was 8 min (6$10 \mathrm{mn})$. There were no signs of infection on 3rd day. 6 patients $(18.75 \%)$ had redness and erythema around the suture at the time of suture removal, which were followed up 2 days after the suture removal and found to be settled. None of the patients developed infection. There were no recurrences upto 3 moths follow up. Four patients (12.5\%) reported back with recurrence and all of them were dorsal ganglion. One patient $(3.125 \%)$ had recurrence at at 4 months and was painful and he had to undergo excision and the biopsy showed tuberculosis. Remaining $3(10 \%)$ had recurrence around 9 months post procedure which were small in size and asymtomatic and all three decided to wait.

\section{Case 1}

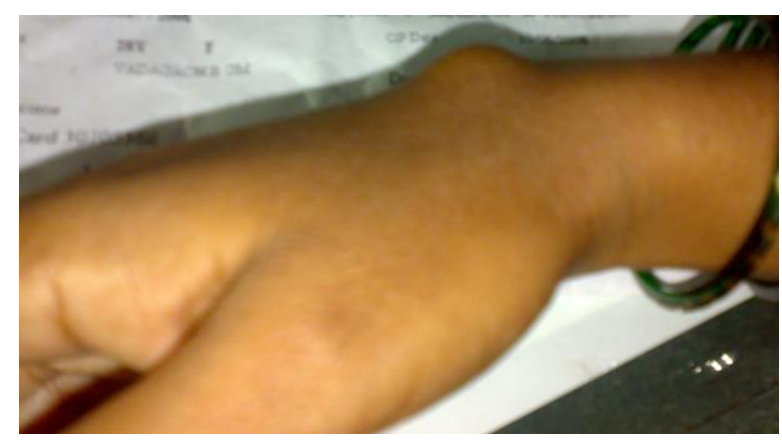

Fig 1: Pre-Op

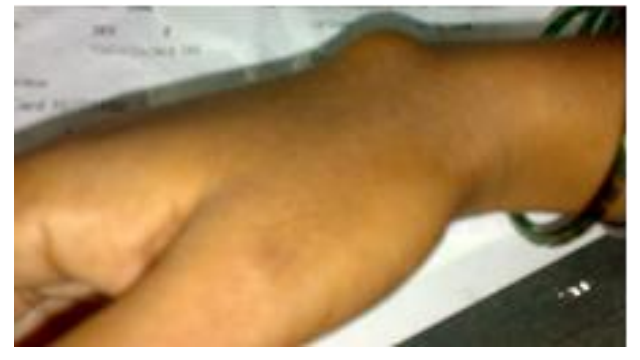

Fig 2: Pre-Op

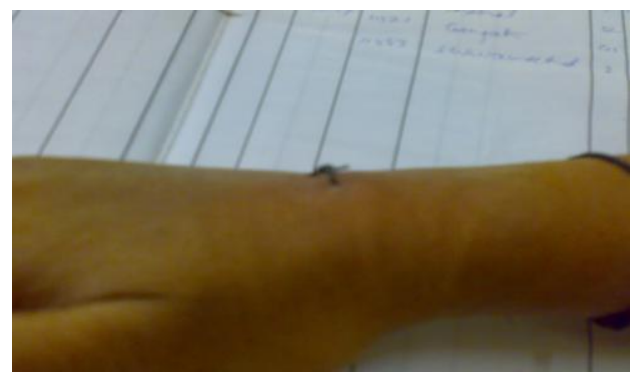

Fig 3: Suture in Place

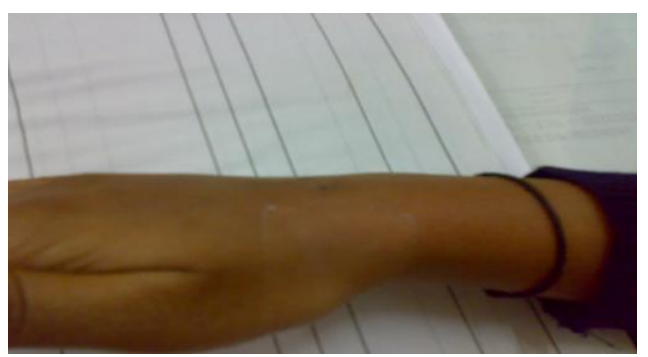

Fig 4: Suture Removed $7^{\text {th }}$ Day

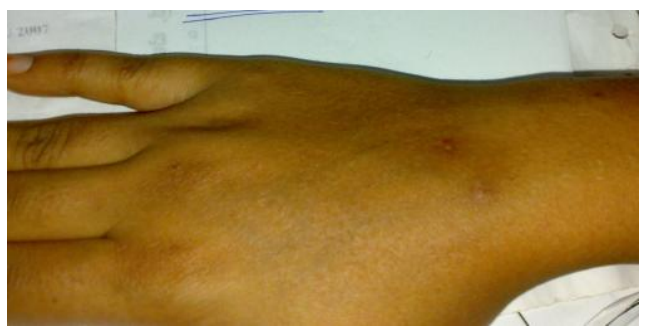

Fig 5: 3 Months

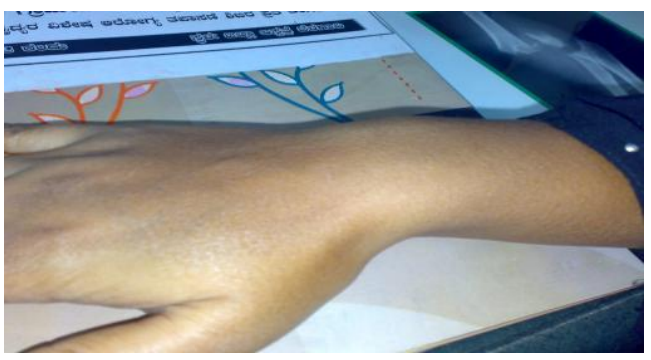

Fig 6: 9 Months

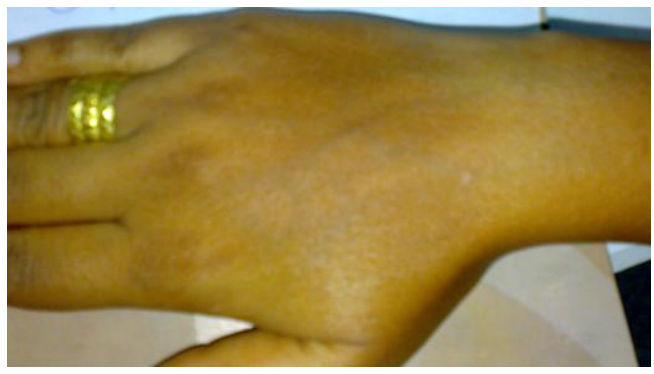

Fig 7: 9months 
Case 2

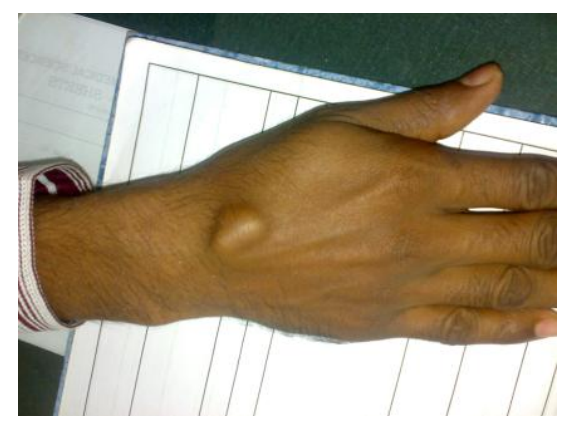

Fig 1: Pre-Op

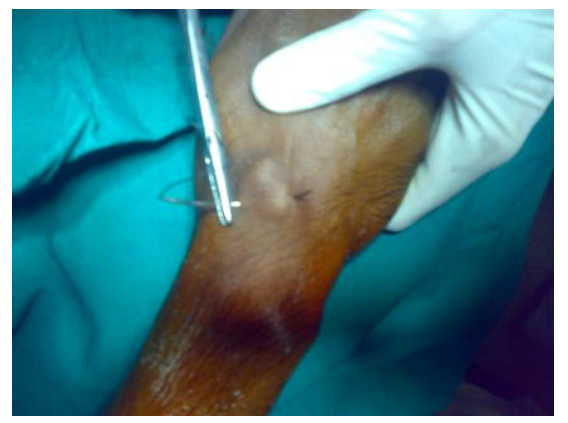

Fig 2: Needling

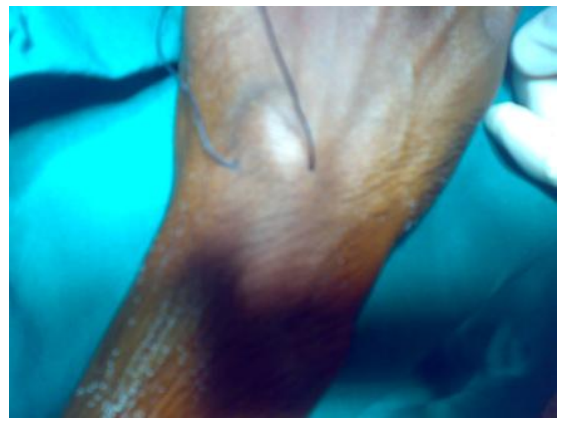

Fig 3: Suture in Place

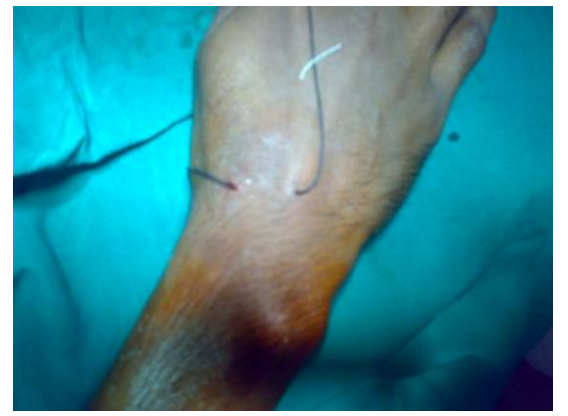

Fig 4: Contents Expressed

\section{Discussion}

Ganglion are one most common soft tissue tumors encountered ${ }^{[6]}$. In-spite of the common occurrence of these cystic lesion, there are various treatment protocols practiced till date. Different treatments, which are explained range from, historically hitting with book /bible ${ }^{[7]}$, aspiration alone ${ }^{[5]}$ or combined with steroid ${ }^{[6.9]}$ or hyloronic acid injection ${ }^{[4]}$ and lastly surgical excision ${ }^{[2,3]}$. Comparison of surgical excision with aspiration and steroid injection showed wide gap in the results ${ }^{[6]}$, with success rate of around $94 \%$ for surgical excision and mere $61 \%$ for aspiration and steroid injection. Varley et al in their study found only $33 \%-57 \%$ success rates with either aspiration alone or in combination with steroid injection ${ }^{[8,9]}$ but when combined aspiration with hyaloronidase and triamcinalone injection, the success rate shot upto $89 \%{ }^{[8]}$. Surgical excision and closure of capsule has found to be more successful of all treatment option with success rates of around $92 \%{ }^{[2,3]}$. Only other treatment which comes close to the success rate of the surgical excision is treatment of ganglion using thread or suture to transfix the ganglion. This method has been found to be comparable to the results of surgical excision with success rates around $92 \%$ [1, ${ }^{4]}$.In our series, we studied 32 patients with ganglion treated with transfixation using Mersilk no 1 , which we called it as NEEDLING, was used as method of treatment. The success rates for this method was 90\% (excluding the the case diagnosed as tubercular ganglion).This is simple method of treatment, has low complication rates and is inexpensive. Unlike other suture material, silk used in this method helps in making track for escape of ganglion contents following initial procedure. And retaining suture lets the contents escape out and it produces fibrosis within ganglion lining. Thus reducing the chances of recurrences, compared to plain needling. This procedure can be carried out in out patient department and done under local anaesthesia. As many of the patients come for treatment for cosmetic reason, this procedure of needling scores over surgical excision, in terms of results as well as cosmesis.

\section{Conclusion}

This procedure of NEEDLING (as we call it), i.e, use of mersik as transfixation suture in the treatment of Ganglion reemphasises that it is more cosmetically acceptable, with low complication rates, and low recurrence rates. It can be best alternative to surgical excision of ganglion

\section{References}

1. Rathod CM, Nemade AS, Badole CM; Treatment of dorsal wrist ganglia by transfixation technique; Niger $\mathrm{J}$ ckin Pract. 2011; 14:445-8

2. Craik JD1, Walsh SP. Patient outcomes following wrist ganglion excision surgery. J Hand Surg Eur. 2012; 37(7):673-7. doi: 10.1177/1753193411434376. Epub 2012

3. de Villiers CM1, Birnie RH, Pretorius LK, Vlok GJ; Dorsal ganglion of the wrist--pathogenesis and biomechanics. Operative v. conservative treatment; S Afr Med J. 1989; 75(5):214-6.

4. Gang RK1, Makhlouf S; Treatment of ganglia by a thread technique; J Hand Surg Br. 1988; 13(2):184-6.

5. Head L1, Allen M2, Boyd KU2. Long-term outcomes and patient satisfaction following wrist ganglion aspiration; Plast Surg (Oakv). 2015; 23(1):51-3.

6. Khan PS1, Hayat H. Surgical excision versus aspiration combined with intralesional triamcinolone acetonide injection plus wrist immobilization therapy in the treatment of dorsal wrist ganglion; a randomized controlled trial; J Hand Microsurg. 2011; 3(2):55-7. doi: 10.1007/s12593-011-0039-6. Epub 2011 Apr 20.

7. Nelon CL, Sawmiller S, PhaenGS, Ganglion of the wrist and hand. JBJS Am. 1972; 54;1459-64

8. Paul AS1, Sochart DH. Improving the results of ganglion aspiration by the use of hyaluronidase; J Hand Surg Br. 1997; (2):219-21.

9. Varley GW1, Needoff M, Davis TR, Clay NR; Conservative management of wrist ganglia. Aspiration versus steroid infiltration; J Hand Surg Br. 1997; 22(5):636-7. 